\title{
Needle insertion in the foramen ovale
}

\author{
Ignacio Arrese • Enrique Úrculo
}

Received: 1 July 2010 /Accepted: 4 August 2010 / Published online: 2 September 2010

(C) Springer-Verlag 2010

We have read with great interest the article written by Grunert: "An alternative projection for fluoroscopic-guided needle insertion in the foramen ovale: technical note" [1]. As the authors have explained, the foramen ovale is not properly visualized under biplane fluoroscopy, making the insertion of the needle difficult to reach the Gasserian ganglion. In our own experience, this problem forces us in some cases to use high doses of X-ray in an attempt to locate the foramen ovale.

At our Centre, we have recently started to use neuronavigation to solve this hurdle. After getting a CT-scan centered at the cranial base and loading it on the neuronavigation system, we insert the magnetic guide inside the needle. This allows us to reach the foramen ovale displaying it in three dimensions. In the four cases of balloon compression in which this technique has been used, we have not needed fluoroscopy to insert the needle in the foramen ovale and that insertion has been very simple.

However, in the case of the percutaneous compression of the Gasserian ganglion, the use of neuronavigation does not exclude the need of fluoroscopy in order to ensure the good position of the balloon into the Meckle's cave. Despite a rigorous puncture technique, the only manner to ascertain the appropriate location of the catheter is checking the shape of the inflated balloon; when the appearance is not the typical "pear-shaped" one, it is better if immediately deflated and the needle repositioned.

In summary, we support the utility of new methods to make the needle insertion easier in the foramen ovale, as the fluoroscopic projection reported by Grunert et al. or the use of neuronavigation proposed by us.

Conflicts of interest None.

\section{Reference}

1. Grunert P, Glaser M, Kockro R, Boor S, Oertel J (2010) An alternative projection for fluoroscopic-guided needle insertion in the foramen ovale: technical note. Acta Neurochir (Wien) (in press)

I. Arrese $(\bowtie) \cdot$ E. Úrculo 